\title{
Sulfonated Mesoporous Silica-Carbon Composite Derived from a Silicate-Polyethylene Glycol Gel and Its Application as Solid Acid Catalysts
}

\author{
Shofiyya Julaika, Agus Farid Fadli, W. Widiyastuti, Heru Setyawan* \\ Department of Chemical Engineering, Faculty of Industrial Technology and System Engineering, \\ Sepuluh Nopember Institute of Technology, Kampus ITS Sukolilo, Surabaya 60111, Indonesia.
}

Received: 22 $2^{\text {nd }}$ July 2021; Revised: $13^{\text {th }}$ October 2021; Accepted: $13^{\text {th }}$ October 2021

Available online: 20th October 2021; Published regularly: March 2022

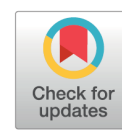

\section{Abstract}

Solid acid catalyst is a promising alternative to the counterpart homogeneous acid for esterification reaction from the viewpoint of reusability and environmental concerns. This work aims to develop sulfonated mesoporous silicacarbon composite as solid acid catalyst for the esterification. The catalyst was synthesized from sodium silicate as the silica precursor and polyethylene glycol (PEG) as both carbon precursor and template via a sol-gel route in an aqueous system. Then, it was carbonized to produce mesoporous silica-carbon composite. Using the proposed method, the surface area of the silica-carbon composite could reach as high as $1074.21 \mathrm{~m}^{2} / \mathrm{g}$. Although the surface area decreased to $614.02 \mathrm{~m}^{2} / \mathrm{g}$ when it was functionalized with sulfonate groups, the composite had a high ionic capacity of $5.3 \mathrm{mEq} / \mathrm{g}$ and exhibited high catalytic activity for esterification reaction of acetic acid with ethanol. At a reaction temperature of $80{ }^{\circ} \mathrm{C}$, the acetic acid conversion reached $76.55 \%$ in $4 \mathrm{~h}$. In addition, the catalyst had good reusability, which can be comparable with the commercial catalyst Foltrol F-007. It appears that the sulfonated silica-carbon composite prepared from sodium silicate using PEG as the carbon source a promising candidate as catalyst for esterification and the related area.

Copyright (C) 2021 by Authors, Published by BCREC Group. This is an open access article under the CC BY-SA License (https://creativecommons.org/licenses/by-sa/4.0).

Keywords: Solid acid; heterogeneous catalyst; sulfonation; silica-carbon; esterification; carbonization

How to Cite: S. Julaika, A.F. Fadli, W. Widiyastuti, H. Setyawan (2022). Sulfonated Mesoporous Silica-Carbon Composite Derived from a Silicate-Polyethylene Glycol Gel and Its Application as Solid Acid Catalysts. Bulletin of Chemical Reaction Engineering \& Catalysis, 17(1), 13-21 (doi:10.9767/bcrec.17.1.11795.13-21)

Permalink/DOI: https://doi.org/10.9767/bcrec.17.1.11795.13-21

\section{Introduction}

Esters are essential chemicals that are commonly produced industrially by homogeneous acid catalyzed esterification reaction between alcohols and fatty acid. Since esterification is an equilibrium reaction, the acid catalyst is used to speed up the reaction and to direct the reaction path to ester formation. The main drawbacks encountered with homogeneous acid catalysts are the difficulties in separating them from the

* Corresponding Author.

Email: sheru@chem-eng.its.ac.id (H. Setyawan);

Tel.: +62-31-5946240, Fax: +62-31-5999282 reaction mixture and their environmentally unfriendly characteristics, e.g., toxic and corrosiveness to equipment. Solid acid catalyst have shown promising alternative to the homogeneous acid catalyst as indicated by the extensive studies conducted to develop them [1-4].

Among several classes of material that have been developed for use as solid acid catalyst, e.g., ion exchange resin [5], silica-based materials [6,7], carbon-based materials [8-10], and silica-carbon composites [11-15], mesoporous silica-carbon composites have attracted much more attention. The open-pore characteristics of mesoporous silicas combined with the easy function- 
alization of carbon materials offer advantages for its application as solid acid catalyst $[1,14,16,17]$. In addition, mesoporous silicas also possess high thermal/mechanical stability and large pore volumes that provide accessible diffusion pathway that make it suitable for processes involving large molecules. This differs from carbon-based materials obtained by carbonization of carbon precursor through pyrolysis or hydrothermal process that mainly consists of microporous domains that limit their application for large molecules [18]. Although ordered mesoporous carbons (OMCs) can provide large pore volumes for such purposes, they are typically prepared using ordered mesoporous silicas as templates that involves hydrofluoric acid for the template removal $[9,19,20]$.

Mesoporous silica-carbon composite is typically synthesized through a three-step method $[13,21]$. The first step is preparation of mesoporous silica framework, such as SBA 15, KIT 6 and MCM 41. The second step is impregnation of carbon precursor into the silica pores and the third step is carbonization of carbon precursor at high temperature under inert atmosphere. To reduce the preparation step, Valle-Vigón et $a l$. directly carbonized the surfactant template to obtain ordered mesoporous silica-carbon composite [12,22]. However, this method involves a mild surfactant removal that need to be controlled very carefully to provide high concentration of silanol groups to anchor carbon precursors. Otherwise, homogeneous layer of carbon coating could not be realized. Yokoi et al. carbonized surface-alkoxylated silica produced by esterification of furfuryl alcohol with the silanol groups on the surface of mesoporous silica to obtain silica-carbon composite [15].

Previously, we have successfully prepared silica-polyethylene glycol (PEG) composite starting from a cheap and non-toxic silicate in an aqueous system [23,24]. Mesoporous silica was formed when PEG was removed completely, either by calcination or solvothermal method, and it could be functionalized easily with hygroscopic salt. If the PEG was partially removed and at the same time carbonized by heating under inert atmosphere, silica-carbon composite might be produced. Sulfonation of the carbon layer remaining inside the silica pores might become a simple way to fabricate solid acid catalyst with accessible pores.

In the present work, we propose an inexpensive method for producing sulfonated mesoporous silica-carbon composites starting from a sodium silicate solution using PEG as both a templating agent and a carbon precursor. The method involves the formation of a silica-PEG composite gel through a sol-gel reaction in an aqueous system. Upon partially PEG removal and carbonization process of the composite gel, carbon layer is preserved inside the silica pores. The silica-carbon composite was then sulfonated with sulfuric acid to distribute the sulfonate groups along the porosity. The composites were then used as catalysts in the esterification of acetic acid with ethanol.

\section{Materials and methods}

\subsection{Materials}

The materials used to prepare mesoporous silica-carbon composite were industrial grade sodium silicate solution (water glass; $28 \% \mathrm{SiO}_{2}$, $\mathrm{SiO}_{2}: \mathrm{Na}_{2} \mathrm{O}=3.3$, provided by PT. PQ Silica Indonesia) as the silica source and polyethylene glycol (PEG 1000, reagent grade, Merck) as both the template and carbon source. Other chemicals used were hydrochloride acid $(\mathrm{HCl}$ $37 \%$, Merck), sodium hydroxide $(\mathrm{NaOH}$, Merck), and sulfuric acid $\left(\mathrm{H}_{2} \mathrm{SO}_{4} 98 \%\right.$, Merck). They were reagent grade and used as received without further purification. Demineralized water was used during all synthesis and treatment processes.

\subsection{Preparation of Mesoporous Silica-Carbon Composite}

The preparation of mesoporous silica-carbon composite basically included two steps: (i) preparation of silica-PEG composite and (ii) carbonization. The preparation of mesoporous silicaPEG composite follows our developed procedure with some modifications [23]. Briefly, 30 $\mathrm{mL}$ of sodium silicate solution containing $8.0 \%$ of silica was added to $75 \mathrm{~mL}$ of acidic $(0.6 \mathrm{M}$ $\mathrm{HCl}$ ) PEG (3 g) solution under stirring. The $\mathrm{pH}$ was then adjusted to 4 by adding $\mathrm{NaOH}$ solution under the stirring drop by drop. The mixture was aged at room temperature for $1 \mathrm{~h}$ to form a gel and dried in an oven at $80^{\circ} \mathrm{C}$ for 18 $h$. Then, it was washed with demineralized water to remove $\mathrm{NaCl}$ byproduct and dried to produce silica-PEG composite.

To produce silica-carbon composite, the silica-PEG composite was carbonized to convert the PEG in the composite into carbon adhering as thin layer on the surface of the threedimensional structure of silica network. The carbonization was carried out in a tubular furnace under flowing of nitrogen gas. The carbonization temperature was set constant at 450 , 550 , and $750{ }^{\circ} \mathrm{C}$ with a heating time varied from 1 to $5 \mathrm{~h}$. The heater was then turned off, and the sample was allowed to cool to room 
temperature to be used as raw material to produce solid acid catalyst.

\subsection{Sulfonation of Silica-Carbon Composite}

The as-prepared mesoporous silica-carbon composite was sulfonated using sulfuric acid under nitrogen atmosphere. One gram of the mesoporous silica-carbon composite was dispersed in $25 \mathrm{~mL} 98 \%$ sulfuric acid. The mixture was heated at $150{ }^{\circ} \mathrm{C}$ under constant stirring. The sulfonation time was varied for 5 and $10 \mathrm{~h}$. After heating, the mixture was allowed to cool to room temperature and demineralized water was added to dilute the sulfuric acid. The solid was filtered from the mixture and washed with demineralized water to remove residual sulfuric acid. The complete removal was indicated by the absence of white precipitate in the wastewater used for washing when $\mathrm{BaCl}_{2}$ was added. The solid sample was then dried and stored for characterization.

\subsection{Characterizations}

The porosity properties of the samples were determined by nitrogen adsorption-desorption at its boiling point using a gas adsorptiondesorption instrument (Nova 1200, Quantachrome). Prior to the measurements, the samples were degassed at $150{ }^{\circ} \mathrm{C}$ under flowing of nitrogen gas for $5 \mathrm{~h}$ for silica-PEG samples and at $300{ }^{\circ} \mathrm{C}$ for $3 \mathrm{~h}$ for other samples. The specific surface area was calculated using the multi-point Brunauer-Emmet-Teller (BET) method at $\mathrm{P} / \mathrm{P}_{0}<0.3$. The total pore volume was determined at $\mathrm{P} / \mathrm{P}_{0}$ approaching unity. The average pore size and pore size distribution was estimated from the desorption profile using the Barrett-Joyner-Halenda (BJH) model. The morphology and chemical composition of the sample were determined by a scanning electron microscopy/energy-dispersive Xray spectroscopy (SEM-EDX, JET-2300, JEOL).

The ionic capacity of the sulfonated-samples was determined by acid-base titration method. The sample was immersed in $25 \mathrm{~mL}$ of $1 \mathrm{~N}$ $\mathrm{NaOH}$ solution for $48 \mathrm{~h}$ to react the sulfonate group on the sample with $\mathrm{NaOH}$. The solid sample was filtered, and the filtrate was diluted and titrated with standardized $0.1 \mathrm{M} \mathrm{HCl}$ solution to determine the remaining $\mathrm{NaOH}$ concentration after immersion. The ionic capacity was then calculated by the number of moles of $\mathrm{NaOH}$ reacted with the sulfonate group divided by the initial mass of sample immersed.

\subsection{Esterification of Acetic Acid with Ethanol}

The esterification of acetic acid with methanol in the presence of sulfonated-mesoporous silica-carbon composite was performed in a three-neck flask under reflux. The reaction mixture comprised of $40 \mathrm{~mL}$ ethanol $(99.9 \%$, p.a., Merck) and $20 \mathrm{~mL}$ acetic acid (100\%, glacial, Merck) with a catalyst loading of $0.2 \mathrm{~g}$ per $20 \mathrm{~mL}$ acetic acid. The reaction was carried out for $4 \mathrm{~h}$ under constant stirring with a temperature varied from 60 to $80^{\circ} \mathrm{C}$. During reaction, 1 $\mathrm{mL}$ of aliquots was sampled periodically from the reaction mixture for analysis. The acetic acid concentration in the aliquot was quantitatively analyzed using a gas chromatography (GC-model, Shimadzu 2010 series) equipped with a column (DB-WAX 122-7032, Agilent) and a flame ionization detector (FID). The column was operated at $12{ }^{\circ} \mathrm{C} / \mathrm{min}$ ramp from 35 ${ }^{\circ} \mathrm{C}$ up to $240{ }^{\circ} \mathrm{C}$, kept for $5 \mathrm{~min}$. The carrier gas was nitrogen with a flow rate of $2.5 \mathrm{~mL} / \mathrm{min}$ and the volume of sample injected was $0.5 \mu \mathrm{L}$. The concentration of acetic acid was determined by external calibration and the reaction conversion was calculated by:

$$
X_{A}=\frac{C_{A 0}-C_{A}}{C_{A 0}} \times 100 \%
$$

where, $C_{A 0}$ and $C_{A}$ are, respectively, the initial and final concentrations of acetic acid.

\section{Results and discussions}

\subsection{Characteristic of Silica-Carbon Composite}

Figure 1 presents the effect of carbonization time on the specific surface area of silicacarbon composite at different carbonization temperatures. The surface area of the silicaPEG composite before carbonization was ap-

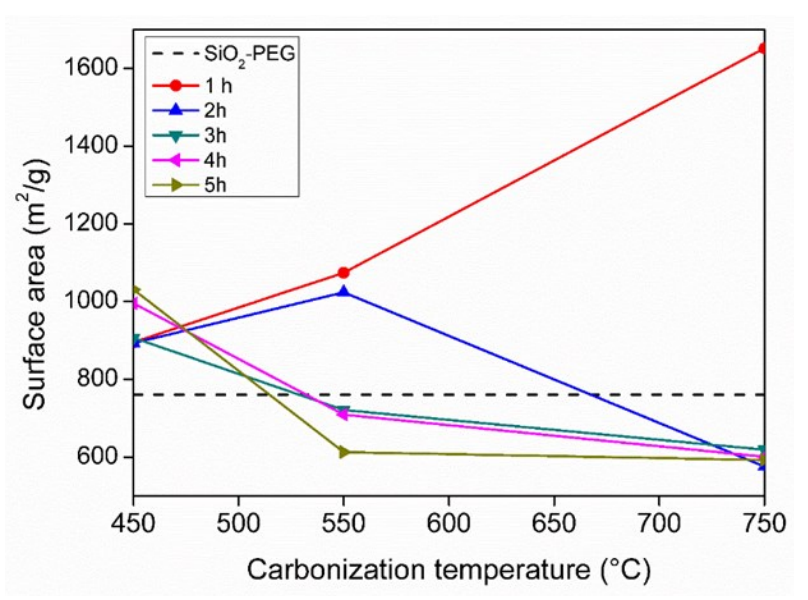

Figure 1. Effect of carbonization temperature on the surface area of mesoporous silica-carbon composites at various carbonization time. 
proximately $760.3 \mathrm{~m}^{2} / \mathrm{g}$. The high surface area of silica-PEG composite may be originated from the behavior of PEG that tends to induce particle aggregation, leading to the formation of an aggregated platelet structure in the silica network [23]. For all carbonization times, the surface area of silica-carbon composite carbonized at $450{ }^{\circ} \mathrm{C}$ was higher than that of the original silica-PEG composite, which range from 893.3 to $1030.8 \mathrm{~m}^{2} / \mathrm{g}$. The surface area tended to decrease with an increase in carbonization temperature when the carbonization time was prolonged $(>1 \mathrm{~h})$. They were even lower than that of the original silica-PEG composite. On the other hand, the surface area of silica-carbon composite carbonized for $1 \mathrm{~h}$ tends to increase with an increase in carbonization temperature, from $895.6 \mathrm{~m}^{2} / \mathrm{g}$ at $450{ }^{\circ} \mathrm{C}$ to $1074.2 \mathrm{~m}^{2} / \mathrm{g}$ and $1651.5 \mathrm{~m}^{2} / \mathrm{g}$ at carbonization temperature of, respectively, 550 and $750{ }^{\circ} \mathrm{C}$.

The increase in the surface area of silicacarbon composite with an increase in temperature at carbonization time of $1 \mathrm{~h}$ was followed by an increase in the pore size and pore volume (Table 1). For example, the pore size and pore volume of silica-carbon composite carbonized at $550{ }^{\circ} \mathrm{C}$ was $3.43 \mathrm{~nm}$ and $0.67 \mathrm{~cm}^{3} / \mathrm{g}$, respectively, and they increased to $3.68 \mathrm{~nm}$ and 1.52 $\mathrm{cm}^{3 / g}$ for carbonization temperature of $750{ }^{\circ} \mathrm{C}$.

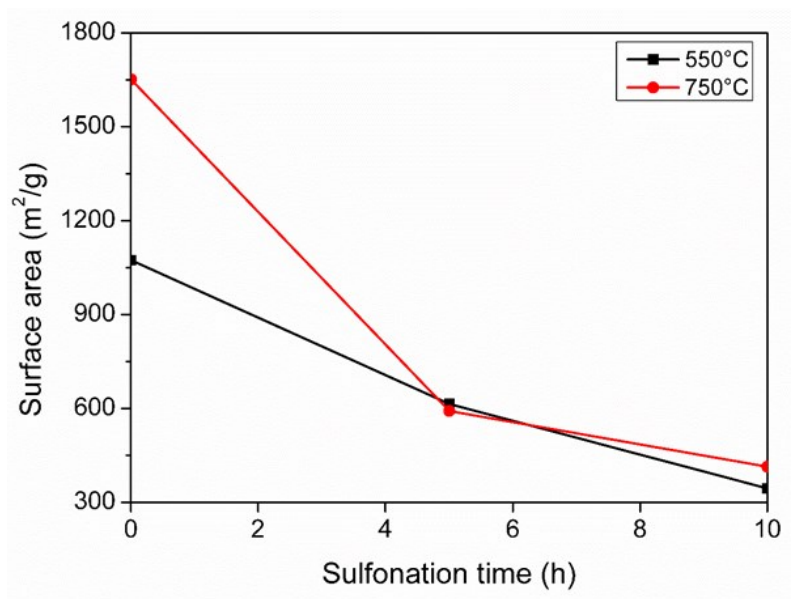

Figure 2. Effect of sulfonation time on the surface area of silica-carbon composite sulfonated at $150^{\circ} \mathrm{C}$ under nitrogen atmosphere. The carbonization was carried out at a temperature of 550 and $750{ }^{\circ} \mathrm{C}$.
On the contrary, the pore size and pore volume were relatively independent on temperature when the carbonization time was longer than 1 $\mathrm{h}$ which took the value of approximately 3.0 $\mathrm{nm}$ and $0.7 \mathrm{~cm}^{3} / \mathrm{g}$, respectively. During carbonization process, the non-carbon elements are released from PEG, enriching carbon content through condensation and pyrolysis reactions [25]. The pyrolysis reactions produce many pores left by the release of the small, noncarbon molecules. However, when the carbonization time was prolonged, the condensation reactions produce many products that may not easily be released from the pores. These may be also the reason why the surface area decreases with the increase of carbonization time.

\subsection{Characteristics of Catalysts}

Figure 2 shows the effect of sulfonation time on the surface area of sulfonated silica-carbon composites. It can be observed that the surface area tended to decrease after sulfonation. The initial surface area of silica carbon composite carbonized at 550 and $750{ }^{\circ} \mathrm{C}$ was approximately 1074.2 and $1651.5 \mathrm{~m}^{2} / \mathrm{g}$, respectively. The surface area was reduced to 614.02 and $591.88 \mathrm{~m}^{2} / \mathrm{g}$ for sulfonation temperature of 550 and $750{ }^{\circ} \mathrm{C}$, respectively, at sulfonation time of $5 \mathrm{~h}$, and lower further when the sulfonation time was prolonged. The surface areas were derived from the $\mathrm{N}_{2}$ adsorption-desorption isotherms shown in Figure 3(a). The $\mathrm{N}_{2}$ sorption isotherms revealed that all porous materials, i.e. PEG-templated silica, silica-PEG composite, silica-carbon composite, sulfonated silicacarbon composite, showed type IV isotherm which correspond to mesoporous structure according to IUPAC classifications [23,24]. The porous silica obtained with PEG template demonstrated the type $\mathrm{H} 2$ of hysteresis that involves a vapor-percolation threshold of the boundary curve occurring at a relative pressure of approximately 0.42 [24]. On the other hand, other samples exhibited the type H4 hysteresis loop indicating slit-shaped pores existing in the samples [26]. The pore volume and pore size also decreased after sulfonation process. The pore volume, for example, decreased from $0.83 \mathrm{~cm}^{3} / \mathrm{g}$ for silica-carbon composite ob-

Table 1. Effect of carbonization temperature on the pore size and pore volume of silica-carbon composite carbonized for $1 \mathrm{~h}$.

\begin{tabular}{lcc}
\hline Carbonization temperature $\left({ }^{\circ} \mathrm{C}\right)$ & Pore volume $\left(\mathrm{cm}^{3} / \mathrm{g}\right)$ & Pore size $(\mathrm{nm})$ \\
\hline 450 & 0.67 & 2.98 \\
550 & 0.83 & 3.43 \\
750 & 1.52 & 3.68 \\
\hline
\end{tabular}


tained at carbonization temperature of $550{ }^{\circ} \mathrm{C}$ to $0.43 \mathrm{~cm}^{3} / \mathrm{g}$. As shown in Figure 3(b), although the pore sizes decrease after sulfonation, the pore sizes are still above the lower boundary of pore size range of mesoporous materials. The reduction in surface area, pore volume and pore size of the sulfonated silica-carbon composite as described above suggests that sulfonate $\left(-\mathrm{SO}_{3} \mathrm{H}\right)$ groups are not only attached on surface of silica-carbon composite but also fill the pore openings [16].

Figure 4 shows the SEM images showing the morphology of the silica-PEG composite (a) and the corresponding silica-carbon composite
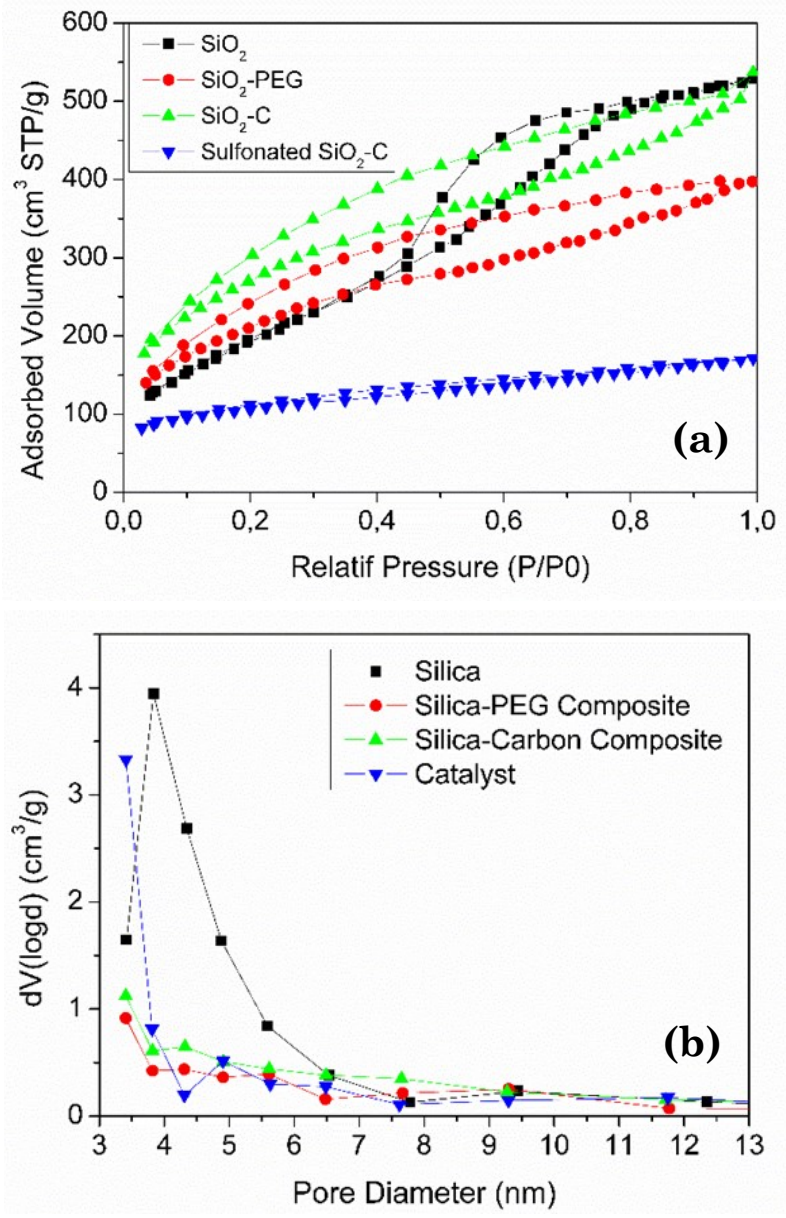

Figure 3. (a) $\mathrm{N}_{2}$ adsorption-desorption isotherms at $77 \mathrm{~K}$ of the porous silica, silica-PEG composite, silica-carbon composite and sulfonated silica carbon composite. (b) The corresponding pore size distribution of the samples. carbonized at $550{ }^{\circ} \mathrm{C}$ for $1 \mathrm{~h}$ (b) and further sulfonated with sulfuric acid (c). All particles had a well-defined spherical shape with smooth surface of approximately $2.9 \mu \mathrm{m}$ in diameter for silica-PEG composite and decreases slightly to approximately $2.5 \mu \mathrm{m}$ after carbonization.
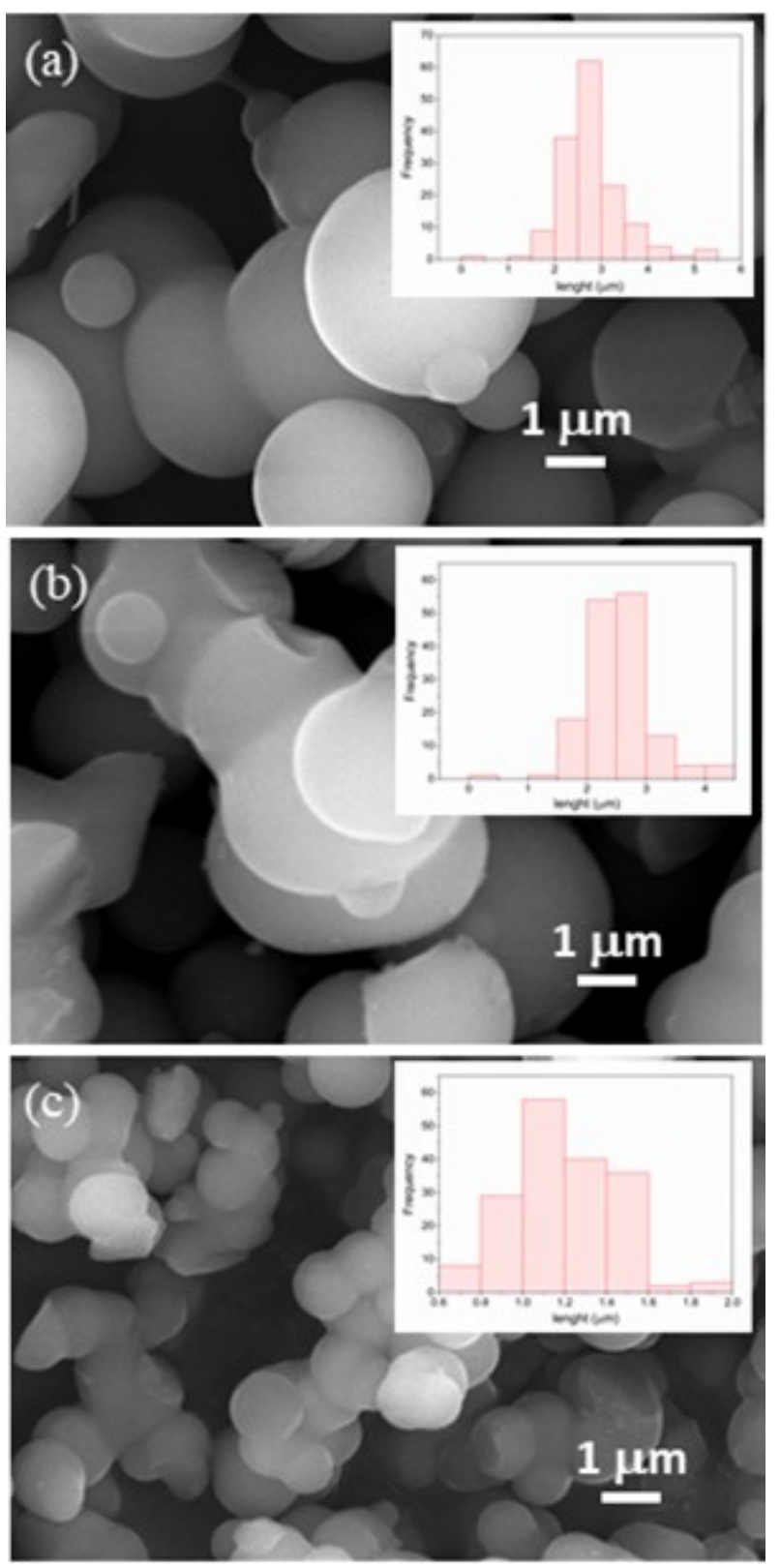

Figure 4. SEM images and particle size distribution (inset) of silica-PEG composite (a), silica-carbon composite (b) and sulfonated silicacarbon composite (c).

Table 2. The composition of silica-PEG, silica-carbon and sulfonated silica-carbon composites.

\begin{tabular}{cccc}
\hline \multirow{2}{*}{ Element } & \multicolumn{3}{c}{ Composition (wt\%) } \\
\cline { 2 - 4 } & Silica-PEG & Silica-carbon & Catalyst \\
\hline $\mathrm{C}$ & 39.54 & 34.17 & 56.89 \\
$\mathrm{O}$ & 31.74 & 33.93 & 22.34 \\
$\mathrm{Si}$ & 27.62 & 28.98 & 19.05 \\
$\mathrm{~S}$ & - & - & 0.17 \\
\hline
\end{tabular}


The elemental composition of the silica-PEG composite, silica-carbon composite and catalyst obtained from EDX analysis is shown in Table 2 . This shows the existence of other materials which are evaporated, in this case, including the reduction of carbon element. An additional element attached to the catalyst compared to the previous composite is sulfur, which is $0.17 \%$ mass. This shows that the sulfonation process has successfully introduced sulfonate groups into the silica-carbon composite.

It is expected that silica-carbon composites having high surface area are beneficial for catalytic reactions. Hence, the silica-carbon composites produced using the above method that have high specific surface area were sulfonated for use as solid acid catalyst. Figure 5 shows the effect of surface area on the ionic capacity of the sulfonated silica-carbon composites. The measurements were carried out in triplicate and the margins of error of the measurements were displayed as error bar in the figures. In general, the ionic capacity increased with increasing the surface area and it could reach ap-

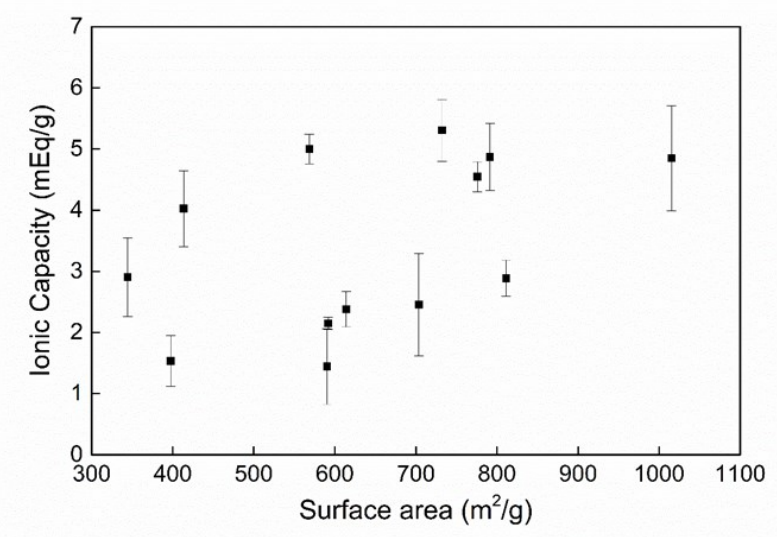

Figure 5. The dependence of the ionic capacity of the sulfonated silica-carbon composite on the surface area of the samples.

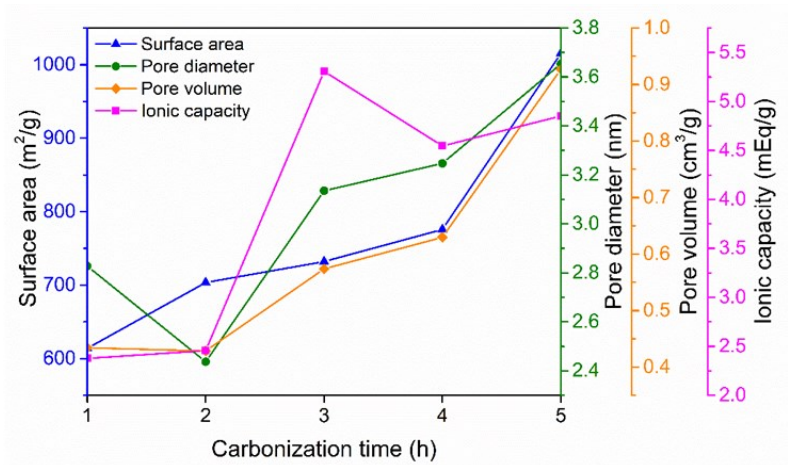

Figure 6. Effect of carbonization time on properties of acid catalyst. The carbonization was carried out at $550{ }^{\circ} \mathrm{C}$ and the sulfonation was at $150^{\circ} \mathrm{C}$ for $5 \mathrm{~h}$. proximately $5.3 \mathrm{mEq} / \mathrm{g}$ at high surface area. This value was comparable to ionic capacity of the sulfonated carbon aerogel derived from coir fibers $(4.45 \mathrm{mEq} / \mathrm{g})$ and of the commercial Flotrol F-007 (4.5 mEq/g), a commonly used catalyst in esterification industries [1].

To conclude, the carbonization time influenced the properties of the composite including surface area, pore size and pore volume and, in turn, the ionic capacity of the sulfonated silicacarbon composites (Figure 6). The surface area, pore volume and pore size tended to increase with the increase of carbonization time. The ionic capacity follows nearly linearly in which it increased with the increase of the three parameters. It appears that the properties of sulfonated silica-carbon composites can be controlled by adjusting the condition of carbonization.

\subsection{Catalytic Activity of the Sulfonated Silica- Carbon Composite}

Figure 7 shows the effect of temperature on acetic acid conversion with a molar ratio of acetic acid:ethanol (1:2) using the sulfonated silica-carbon composite as catalyst. The catalyst used was the sulfonated silica-carbon composite having the specific surface area of 614.02 $\mathrm{m}^{2} / \mathrm{g}$ and the ionic capacity of $5.3 \mathrm{mEq} / \mathrm{g}$. The acetic acid conversion for both cases tended to increase with the elapsed time. For the case of $70{ }^{\circ} \mathrm{C}$, the equilibrium conversion could be reach in a very short time, less than $80 \mathrm{~min}$. However, the equilibrium conversion was very low with only $27 \%$. For the case of $80{ }^{\circ} \mathrm{C}$, it

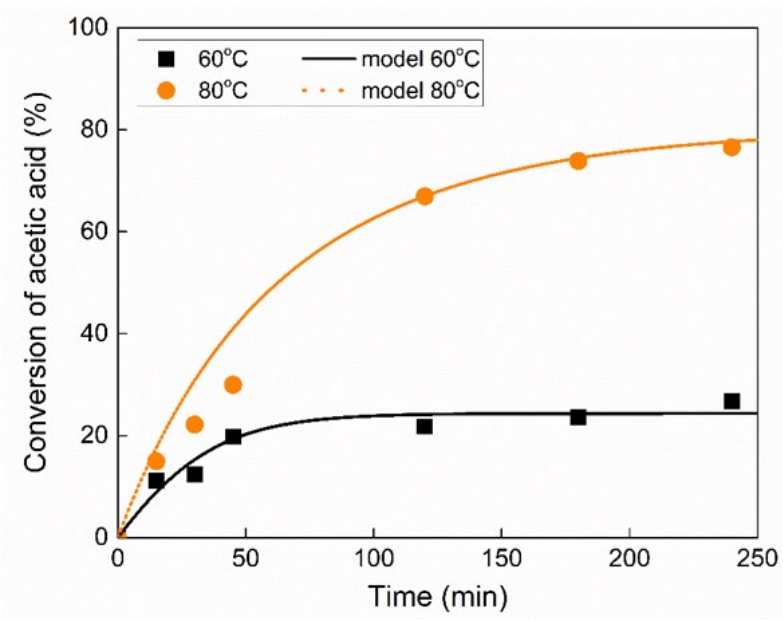

Figure 7. Effect of temperature on acetic acid conversion with a molar ratio of acetic acid:ethanol (1:2) using the sulfonated silicacarbon composite as catalyst. The curves are the prediction using the elementary pseudohomogeneous kinetics model. 
took longer time to reach equilibrium conversion but with a much higher value of conversion that takes a value of approximately $77 \%$.

The above results were analyzed by a simplified kinetic model to determine the kinetic and the equilibrium constants. It was assumed that the reaction was pseudo-homogeneous with a second order elementary reaction that can be expressed as:

$$
\begin{aligned}
-r_{A}=-\frac{d C_{A}}{d t} & =k_{1} C_{A} C_{B}-k_{2} C_{C} C_{D} \\
& =k_{1}\left(C_{A} C_{B}-\frac{C_{C} C_{D}}{K_{e}}\right)
\end{aligned}
$$

where, $C_{A}, C_{B}, C_{C}$, and $C_{D}$ are the concentration of acetic acid, ethanol, ethyl acetate and water, respectively, $k_{1}$ and $k_{2}$ are the forward and backward second order rate constants, and $K_{e}$ is the equilibrium constant of the reaction. The equilibrium constant is related to the rate constant by:

$$
K_{e}=\frac{k_{1}}{k_{2}}
$$

Since the reaction was carried out with a molar ratio of acetic acid to ethanol of $1: 2$ and the products water and ethyl acetate were assumed to be absent at the beginning of the reaction, in term of acetic acid conversion, Equation (3) is modified as:

$$
\frac{d X_{A}}{d t}=k_{1} C_{A 0}\left(2-3 X_{A}+\left(1-\frac{1}{K_{e}}\right) X_{A}^{2}\right)
$$

where, $X_{A}$ is the acetic acid conversion and $C_{A 0}$ is the initial concentration of acetic acid.

Equation (4) was solved numerically using a $4^{\text {th }}$ order Runge-Kutta method in a spreadsheet Excel by trial-and-error of the $k_{1}$ and $K_{e}$ values. The calculated values of $k_{1}$ and $K_{e}$ are presented in Table 3 and the predicted conversions of acetic acid are shown in the Figure 7. It can be observed that the estimated rate and equilibrium constants can predict well the conversion of acetic acid in the heterogeneously catalyzed esterification system. The forward rate constant $k_{1}$ for the reaction at $80{ }^{\circ} \mathrm{C}$ is twofold higher than that of $60^{\circ} \mathrm{C}$ indicating that the esterification reaction proceeds faster at higher temperature. Moreover, the equilibrium constant for esterification at $60^{\circ} \mathrm{C}$ is very low, only one

Table 3. Kinetic parameters of reactions.

\begin{tabular}{ccc}
\hline \multirow{2}{*}{ Parameters } & \multicolumn{2}{c}{ Temperature } \\
\cline { 2 - 3 } & $60{ }^{\circ} \mathrm{C}$ & $80{ }^{\circ} \mathrm{C}$ \\
\hline$k_{1}\left(\mathrm{~L} \cdot \mathrm{mol}^{-1} \cdot \mathrm{min}^{-1}\right)$ & $5.63 \times 10^{-4}$ & $1.16 \times 10^{-3}$ \\
$K_{e}$ & $4.46 \times 10^{-2}$ & 2.72 \\
\hline
\end{tabular}

sixtieth of the equilibrium constant at $80{ }^{\circ} \mathrm{C}$. It means that the equilibrium conversion of esterification reaction taking place at $60{ }^{\circ} \mathrm{C}$ is very low.

The reusability of catalyst is important for any solid catalytic system. Figure 8 shows the reusability of the sulfonated silica-carbon catalyst used for esterification of acetic acid with ethanol (molar ratio 1:2) at $80^{\circ} \mathrm{C}$. For comparison, the reusability a commercial Flotrol F-007 catalyst for the same reaction is also presented. The sulfonated silica-carbon catalyst showed a better catalytic activity in the first cycle compared to Flotrol F-007 catalyst with a conversion of $77 \%$ compared to $67.7 \%$. After each cycle, the catalyst was washed with ethanol and used for the next cycle. The conversion using the sulfonated silica-carbon catalyst decreased to $49.5 \%$ and $35.9 \%$ in, respectively, the second and third cycles. The Flotrol F-007 catalyst also showed a decrease in the catalytic activity in the second and third cycle, but it was better than the sulfonated silica-carbon catalyst. For Flotrol F-007, the conversion decreased to $65.9 \%$ in the second cycle and $57.0 \%$ in the third cycle. Thus, the sulfonated silica-carbon catalyst shows a slightly lower reusability as compared to Flotrol F-007.

The sulfonated silica-carbon composite used to evaluate the catalytic activity of esterification was the one that had the highest surface area $\left(614.02 \mathrm{~m}^{2} / \mathrm{g}\right)$ and highest ionic capacity $(5.3 \mathrm{mEq} / \mathrm{g})$. The high surface area provide more sites for the sulfonate groups to be grafted on the surface of the silica-carbon composite. This, in turn, would provide more active sites for the esterification reaction to take place. As discussed above, the pore size for all

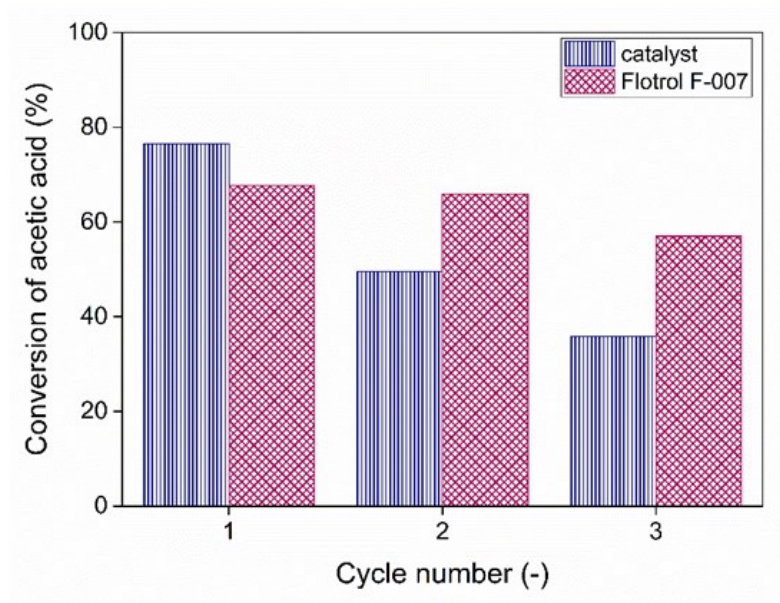

Figure 8. Reusability of sulfonated silicacarbon composite and Flotrol F-007 catalysts at a reaction temperature of $80^{\circ} \mathrm{C}$ for $240 \mathrm{~min}$. 
samples are $>2 \mathrm{~nm}$, so that the materials can be categorized as mesopores according to IUPAC. In this size range, the pore diffusion resistance may be neglected and the overall kinetic reaction is controlled by the surface reaction.

\section{Conclusions}

Mesoporous silica-carbon composite with high surface area has been successfully synthesized using sodium silicate as the silica source and PEG 1000 as both carbon source and pore template. The use of PEG as both the carbon source and the template offer advantage over the two-step method that typically requires impregnation of carbon precursor and carbonization at high temperature. In this current approach, the two steps are carried out simultaneously that can significantly reduce the synthesis time. In addition, the surface area of the mesoporous silica-carbon composite could be controlled by adjusting the amount of PEG. The mesoporous silica-carbon composite was then functionalized with sulfonic acid. It is found that the ionic capacity of the composite is greatly influenced by the specific surface area of the composite, where the higher the surface area is, the higher the ionic capacity is. The obtained sulfonated silica-carbon composite exhibited high activity for catalytic esterification reaction of acetic acid with ethanol. The activity is comparable to the commercial catalyst Foltrol F-007. In addition, the sulfonated silicacarbon catalyst also demonstrated good reusability. The high activity, together with good reusability, makes the sulfonated silica-carbon composite prepared from sodium silicate using PEG as the carbon source a promising candidate as catalyst for esterification and the related area.

\section{Acknowledgements}

This work was supported by the Ministry of Research and Technology of Indonesia through Fundamental Research Grant (No. 3/AMD/E1/KP.PTNBH/2020). One of the authors (S.J.) would like to thank the Ministry of Education and Culture of Indonesia for a doctoral scholarship through BPPDN.

\section{References}

[1] Fauziyah, M., Widiyastuti, W., Setyawan, H. (2020). Sulfonated Carbon Aerogel Derived from Coir Fiber as High Performance Solid Acid Catalyst for Esterification. Adv. Powder Technol., 31, 1412-1419. DOI: 10.1016/j.apt.2020.01.022.
[2] Peng, L., Philippaerts, A., Ke, X., Van Noyen, J., De Clippel, F., Van Tendeloo, G., Jacobs, P.A., Sels, B.F. (2010). Preparation of Sulfonated Ordered Mesoporous Carbon and Its Use for the Esterification of Fatty Acids. Catal. Today, 150, 140-146. DOI: 10.1016/j.cattod.2009.07.066.

[3] Jia, R., Ren, J., Liu, X., Lu, G., Wang, Y. (2014). Design and Synthesis of Sulfonated Carbons with Amphiphilic Properties. J. Mater. Chem. A, 2(29), 11195-11201. DOI: 10.1039/c4ta01836b.

[4] Mardhiah, H.H., Ong, H.C., Masjuki, H.H., Lim, S., Lee, H.V. (2017). A Review on Latest Developments and Future Prospects of Heterogeneous Catalyst in Biodiesel Production from Non-Edible Oils. Renew. Sustain. Energy Rev., 67, 1225-1236. DOI: 10.1016/j.rser.2016.09.036.

[5] Harmer, M.A., Sun, Q. (2001). Solid Acid Catalysis Using Ion-Exchange Resins. Appl. Catal. A Gen., 221, 45-62. DOI: 10.1016/S0926-860X(01)00794-3.

[6] Ziarani, G.M., Lashgari, N., Badiei, A. (2015). Sulfonic Acid-Functionalized Mesoporous Silica (SBA-Pr-SO3H) as Solid Acid Catalyst in Organic Reactions. J. Mol. Catal. A Chem., $397, \quad 166-191$. D O I : 10.1016/j.molcata.2014.10.009.

[7] Margolese, D., Melero, J.A., Christiansen, S.C., Chmelka, B.F., Stucky, G.D. (2000). Direct Syntheses of Ordered SBA-15 Mesoporous Silica Containing Sulfonic Acid Groups. Chem. Mater., 12(8), 2448-2459. DOI: 10.1021/cm0010304.

[8] Hara, M., Yoshida, T., Takagaki, A., Takata, T., Kondo, J.N., Hayashi, S., Domen, K. (2004). A Carbon Material as a Strong Protonic Acid. Angew. Chemie - Int. Ed., 43(22), 2955-2958. DOI: 10.1002/anie.200453947.

[9] Liu, R., Wang, X., Zhao, X., Feng, P. (2008). Sulfonated Ordered Mesoporous Carbon for Catalytic Preparation of Biodiesel. Carbon N. Y., 46(13), 1664-1669. DOI: 10.1016/j.carbon.2008.07.016.

[10] Chabukswar, D.D., Heer, P.K.K.S., Gaikar, V.G. (2013). Esterification of Palm Fatty Acid Distillate Using Heterogeneous Sulfonated Microcrystalline Cellulose Catalyst and Its Comparison with H2SO4 Catalyzed Reaction. Ind. Eng. Chem. Res., 52(22), 7316-7326. DOI: 10.1021/ie303089u.

[11] Yousatit, S., Pitayachinchot, H., Wijitrat, A., Chaowamalee, S., Nuntang, S., Soontaranon, S., Rugmai, S., Yokoi, T., Ngamcharussrivichai, C. (2020). Natural Rubber as a Renewable Carbon Source for Mesoporous Carbon/Silica Nanocomposites. Sci. Rep., 10(1), 1-14. DOI: 10.1038/s41598-020-69963-3. 
[12] Valle-Vigón, P., Sevilla, M., Fuertes, A.B. (2012). Sulfonated Mesoporous Silica-Carbon Composites and Their Use as Solid Acid Catalysts. Appl. Surf. Sci., 261, 574-583. DOI: 10.1016/j.apsusc.2012.08.059.

[13] Björk, E.M., Militello, M.P., Tamborini, L.H., Coneo, R., Planes, G.A., Acevedo, D.F., Moreno, M.S., Odén, M., Barbero, C.A. (2017). Mesoporous Silica and Carbon Based Catalysts for Esterification and Biodiesel FabricationThe Effect of Matrix Surface Composition and Porosity. Appl. Catal. A Gen., 533, 49-58. DOI: $10.1016 /$ j.apcata.2017.01.007.

[14] Shagufta, S., Ahmad, I., Dhar, R. (2017). Sulfonic Acid-Functionalized Solid Acid Catalyst in Esterification and Transesterification Reactions. Catal. Surv. from Asia, 21(2), 53-69. DOI: $10.1007 / \mathrm{s} 10563-017-9226-1$.

[15] Yokoi, T., Seo, S., Chino, N., Shimojima, A., Okubo, T. (2009). Preparation of Silica/Carbon Composites with Uniform and Well-Ordered Mesopores by Esterification Method. Microporous Mesoporous Mater., $124(1-3), \quad 123-130$. D O I : 10.1016/j.micromeso.2009.05.002.

[16] Rao, B.V.S.K., Mouli, K.C., Rambabu, N., Dalai, A.K., Prasad, R.B.N. (2011). CarbonBased Solid Acid Catalyst from de-Oiled Canola Meal for Biodiesel Production. Catal. Commun., 14(1), 20-26. DOI: 10.1016/j.catcom.2011.07.011.

[17] Takagaki, A., Toda, M., Okamura, M., Kondo, J.N., Hayashi, S., Domen, K., Hara, M. (2006). Esterification of Higher Fatty Acids by a Novel Strong Solid Acid. Catal. Today, 116, 157-161. DOI: 10.1016/j.cattod.2006.01.037.

[18] Sun, X., Yu, W., Yan, J., Li, J., Jin, G., Feng, J., Guo, Z., Liang, X. (2018). Mesoporous Silica-Carbon Composites Fabricated by a Universal Strategy of Hydrothermal Carbonization: Controllable Synthesis and Applications. RSC Adv., 8(48), 27207-27215. DOI: 10.1039/c8ra04641g.

[19] Wang, X., Liu, R., Waje, M.M., Chen, Z., Yan, Y., Bozhilov, K.N., Feng, P. (2007). Sulfonated Ordered Mesoporous Carbon as a Stable and Highly Active Protonic Acid Catalyst. Chem. Mater., 19(10), 2395-2397. DOI: $10.1021 / \mathrm{cm} 070278 \mathrm{r}$.
[20] Janaun, J., Ellis, N. (2011). Role of Silica Template in the Preparation of Sulfonated Mesoporous Carbon Catalysts. Appl. Catal. A Gen., $\quad 394(1-2), \quad 25-31$. DOI : 10.1016/j.apcata.2010.12.016.

[21] Das, D., Lee, J.F., Cheng, S. (2001). Sulfonic Acid Functionalized Mesoporous MCM-41 Silica as a Convenient Catalyst for Bisphenol-A Synthesis. Chem. Commun., 21, 2178-2179. DOI: $10.1039 / \mathrm{b} 107155 f$.

[22] Valle-Vigón, P., Sevilla, M., Fuertes, A.B. (2013). Functionalization of Mesostructured Silica-Carbon Composites. Mater. Chem. Phys., 139(1), 281-289. DOI: 10.1016/j.matchemphys.2013.01.036.

[23] Setyawan, H., Yuwana, M., Balgis, R. (2015). PEG-Templated Mesoporous Silicas Using Silicate Precursor and Their Applications in Desiccant Dehumidification Cooling Systems. Microporous Mesoporous Mater., 218, 95-100. DOI: 10.1016/j.micromeso.2015.07.009.

[24] Rahman, N.A., Widhiana, I., Juliastuti, S.R., Setyawan, H. (2015). Synthesis of Mesoporous Silica with Controlled Pore Structure from from Bagasse Ash as a Silica Source. Colloids Surfaces A Physicochem. Eng. Asp., 476, 1-7. DOI: 10.1016/j.colsurfa.2015.03.018.

[25] Ma, Q.S., Gao, A.J., Tong, Y.J., Zhang, Z.G. (2016). The Densification Mechanism of Polyacrylonitrile Carbon Fibers during Carbonization. New Carbon Mater., 31(5), 550-554. DOI: $10.1016 / \mathrm{S} 1872-5805(16) 60031-8$.

[26] Mateo, W., Leix, H., Villota, E., Qian, M., Zhao, Y., Huo, E., Zhang, Q., Lin, X., Wang, C., Huang, Z. (2019). Synthesis and Characterization of Sulfonated Activated Carbon as a Catalyst for Bio-Jet Fuel Production from Biomass and Waste Plastics. Bioresour. Technol., $297, \quad 122411$. D O I : 10.1016/J.BIORTECH.2019.122411. 